\title{
Transcatheter Aortic Valve Replacement With Next-Generation
}

\section{Self-Expanding Devices: A Multicenter, Retrospective, Propensity-Matched} Comparison of Evolut PRO Versus Acurate neo Transcatheter Heart Valves

\author{
Pagnesi, Matteo ; Kim, Won-Keun ; Conradi, Lenard ; et al ; Taramasso, Maurizio ; Saccocci, Matteo ;
} Maisano, Francesco

\begin{abstract}
OBJECTIVES The aim of this study was to compare transcatheter aortic valve replacement (TAVR) with the Acurate neo (NEO) and Evolut PRO (PRO) devices. BACKGROUND The NEO and PRO bioprostheses are 2 next-generation self-expanding devices developed for TAVR. METHODS The NEOPRO (A Multicenter Comparison of Acurate NEO Versus Evolut PRO Transcatheter Heart Valves) registry retrospectively included patients who underwent transfemoral TAVR with either NEO or PRO valves at 24 centers between January 2012 and March 2018. One-to-one propensity score matching resulted in 251 pairs. Pre-discharge and 30-day Valve Academic Research Consortium (VARC)-2 defined outcomes were evaluated. Binary logistic regression was performed to adjust the treatment effect for propensity score quintiles. RESULTS A total of 1,551 patients ( $\mathrm{n}=1,263 \mathrm{NEO} ; \mathrm{n}=288$ PRO) were included. The mean age was 82 years, and the mean Society of Thoracic Surgeons score was $5.1 \%$. After propensity score matching $(\mathrm{n}=502)$, VARC-2 device success $(90.6 \%$ vs. $91.6 \% ; \mathrm{p}=0.751)$ and predischarge moderate to severe (II+) paravalvular aortic regurgitation $(7.3 \%$ vs. $5.7 \%$; p $=0.584)$ were comparable between the NEO and PRO groups. Furthermore, there were no significant differences in any 30-day clinical outcome between matched $\mathrm{NEO}$ and PRO pairs, including all-cause mortality $(3.2 \%$ vs. $1.2 \% ; \mathrm{p}=0.221)$, stroke $(2.4 \%$ vs. $2.8 \% ; \mathrm{p}=1.000)$, new permanent pacemaker implantation (11.0\% vs. $12.8 \% ; \mathrm{p}=0.565)$, and VARC-2 early safety endpoint $(10.6 \%$ vs. $10.4 \% ; \mathrm{p}=1.000)$. Logistic regression on the unmatched cohort confirmed a similar risk of VARC-2 device success, paravalvular aortic regurgitation II+, and 30-day clinical outcomes after NEO and PRO implantation. CONCLUSIONS In this multicenter registry, transfemoral TAVR with the NEO and PRO bioprostheses was associated with high device success, acceptable rates of paravalvular aortic regurgitation II+, and good 30-day clinical outcomes. After adjusting for potential confounders, short-term outcomes were similar between the devices.
\end{abstract}

DOI: https://doi.org/10.1016/j.jcin.2018.11.036

Other titles: M11, F11

Posted at the Zurich Open Repository and Archive, University of Zurich ZORA URL: https://doi.org/10.5167/uzh-178582

Journal Article

Published Version 
The following work is licensed under a Creative Commons: Attribution-NonCommercial-NoDerivatives 4.0 International (CC BY-NC-ND 4.0) License.

Originally published at:

Pagnesi, Matteo; Kim, Won-Keun; Conradi, Lenard; et al; Taramasso, Maurizio; Saccocci, Matteo; Maisano, Francesco (2019). Transcatheter Aortic Valve Replacement With Next-Generation Self-Expanding Devices: A Multicenter, Retrospective, Propensity-Matched Comparison of Evolut PRO Versus Acurate neo Transcatheter Heart Valves. JACC. Cardiovascular interventions, 12(5):433-443.

DOI: https://doi.org/10.1016/j.jcin.2018.11.036 


\title{
Transcatheter Aortic Valve Replacement With Next-Generation Self-Expanding Devices
}

\author{
A Multicenter, Retrospective, Propensity-Matched Comparison \\ of Evolut PRO Versus Acurate neo Transcatheter Heart Valves
}

Matteo Pagnesi, MD, ${ }^{\mathrm{a}}$ Won-Keun Kim, MD, ${ }^{\mathrm{b}}$ Lenard Conradi, MD, ${ }^{\mathrm{c}}$ Marco Barbanti, MD, ${ }^{\mathrm{d}}$ Giulio G. Stefanini, MD, PHD, Tobias Zeus, MD, ${ }^{\mathrm{f}}$ Thomas Pilgrim, MD, ${ }^{\mathrm{g}}$ Joachim Schofer, MD, PHD, ${ }^{\mathrm{h}}$ David Zweiker, MD, ${ }^{\mathrm{i}}$ Luca Testa, MD, ${ }^{\mathrm{j}}$ Maurizio Taramasso, MD, ${ }^{\mathrm{k}}$ David Hildick-Smith, $\mathrm{MD},{ }^{1}$ Alexandre Abizaid, MD, $\mathrm{PHD},{ }^{\mathrm{m}}$ Alexander Wolf, MD, ${ }^{\mathrm{n}}$ Nicolas M. Van Mieghem, MD, PHD, ${ }^{\circ}$ Alexander Sedaghat, MD, ${ }^{\mathrm{p}}$ Jochen Wöhrle, MD, ${ }^{\mathrm{q}}$ Saib Khogali, MD, ${ }^{\mathrm{r}}$ Jan A.S. Van der Heyden, MD, PHD, ${ }^{\mathrm{s}}$ John G. Webb, MD, ${ }^{\mathrm{t}}$ Rodrigo Estévez-Loureiro, MD, PHD, ${ }^{\mathrm{u}}$ Darren Mylotte, MD, ${ }^{\mathrm{v}}$ Philip MacCarthy, MD, ${ }^{\mathrm{w}}$ Salvatore Brugaletta, MD, PHD, ${ }^{\mathrm{x}}$ Christian W. Hamm, MD, ${ }^{\mathrm{b}}$ Oliver D. Bhadra, MD, ${ }^{\mathrm{C}}$ Ulrich Schäfer, MD, ${ }^{\mathrm{y}}$ Giuliano Costa, MD, ${ }^{\mathrm{d}}$ Corrado Tamburino, MD, PHD, ${ }^{\mathrm{d}}$ Francesco Cannata, MD, ${ }^{\mathrm{e}}$ Bernhard Reimers, MD, ${ }^{\mathrm{e}}$ Verena Veulemans, MD, ${ }^{\mathrm{f}}$ Masahiko Asami, MD, ${ }^{\mathrm{g}}$ Stephan Windecker, MD, ${ }^{\mathrm{g}}$ Amnon Eitan, MD, ${ }^{\mathrm{h}}$ Albrecht Schmidt, MD, ${ }^{\mathrm{i}}$ Giovanni Bianchi, MD, ${ }^{\mathrm{j}}$ Francesco Bedogni, MD, ${ }^{\mathrm{j}}$ Matteo Saccocci, MD, ${ }^{\mathrm{k}}$ Francesco Maisano, MD, ${ }^{\mathrm{k}}$ Osama Alsanjari, MD, ${ }^{\mathrm{l}}$ Dimytri Siqueira, MD, ${ }^{\mathrm{m}}$ Christoph J. Jensen, MD, ${ }^{\mathrm{n}}$ Christoph K. Naber, MD, ${ }^{\mathrm{n}}$ Francesca Ziviello, MD, ${ }^{\circ}$ Jan-Malte Sinning, $\mathrm{MD},{ }^{\mathrm{p}}$ Julia Seeger, MD, ${ }^{\mathrm{q}}$ Wolfgang Rottbauer, MD, ${ }^{\mathrm{q}}$ Jorn Brouwer, MD, ${ }^{\mathrm{s}}$ Abdullah Alenezi, MD, ${ }^{\mathrm{t}}$ David A. Wood, MD, Vasileios Tzalamouras, MD, ${ }^{\mathrm{w}}$ Ander Regueiro, $\mathrm{MD},{ }^{\mathrm{x}}$ Antonio Colombo, MD, ${ }^{\mathrm{a}}$ Azeem Latib, $\mathrm{MD}^{\mathrm{a}, \mathrm{z}}$

\section{ABSTRACT}

OBJECTIVES The aim of this study was to compare transcatheter aortic valve replacement (TAVR) with the Acurate neo (NEO) and Evolut PRO (PRO) devices.

BACKGROUND The NEO and PRO bioprostheses are 2 next-generation self-expanding devices developed for TAVR.

METHODS The NEOPRO (A Multicenter Comparison of Acurate NEO Versus Evolut PRO Transcatheter Heart Valves) registry retrospectively included patients who underwent transfemoral TAVR with either NEO or PRO valves at 24 centers between January 2012 and March 2018. One-to-one propensity score matching resulted in 251 pairs. Pre-discharge and 30-day Valve Academic Research Consortium (VARC)-2 defined outcomes were evaluated. Binary logistic regression was performed to adjust the treatment effect for propensity score quintiles.

RESULTS A total of 1,551 patients ( $n=1,263$ NEO; $n=288$ PRO) were included. The mean age was 82 years, and the mean Society of Thoracic Surgeons score was $5.1 \%$. After propensity score matching $(n=502)$, VARC-2 device success ( $90.6 \%$ vs. $91.6 \% ; \mathrm{p}=0.751)$ and pre-discharge moderate to severe (II+) paravalvular aortic regurgitation $(7.3 \%$ vs. $5.7 \% ; \mathrm{p}=0.584$ ) were comparable between the NEO and PRO groups. Furthermore, there were no significant differences in any 30-day clinical outcome between matched NEO and PRO pairs, including all-cause mortality (3.2\% vs. $1.2 \%$; $\mathrm{p}=0.221)$, stroke $(2.4 \%$ vs. $2.8 \% ; \mathrm{p}=1.000)$, new permanent pacemaker implantation $(11.0 \%$ vs. $12.8 \% ; \mathrm{p}=0.565)$, and VARC-2 early safety endpoint $(10.6 \%$ vs. $10.4 \% ; p=1.000)$. Logistic regression on the unmatched cohort confirmed a similar risk of VARC-2 device success, paravalvular aortic regurgitation II+, and 30-day clinical outcomes after NEO and PRO implantation.

CONCLUSIONS In this multicenter registry, transfemoral TAVR with the NEO and PRO bioprostheses was associated with high device success, acceptable rates of paravalvular aortic regurgitation II+, and good 30-day clinical outcomes. After adjusting for potential confounders, short-term outcomes were similar between the devices.

(J Am Coll Cardiol Intv 2019;12:433-43) ๔ 2019 Published by Elsevier on behalf of the American College of Cardiology Foundation. 


\section{ABBREVIATIONS AND ACRONYMS \\ AV = aortic valve \\ $\mathrm{Cl}=$ confidence interval \\ LVOT = left ventricular outflow tract \\ NEO $=$ Acurate neo \\ $O R_{\text {adj }}=$ adjusted odds ratio \\ PAR = paravalvular aortic \\ regurgitation \\ $\mathrm{PPI}=$ permanent pacemaker}

implantation

PRO = Evolut PRO

PS = propensity score

TAVR = transcatheter aortic

valve replacement

THV = transcatheter heart valve

VARC-2 = Valve Academic

Research Consortium-2
T

ranscatheter aortic valve replacement (TAVR) has revolutionized the treatment of patients with severe, symptomatic aortic stenosis, becoming a first-line therapeutic option among patients at increased surgical risk $(1,2)$. As a result of continuous TAVR evolution, several next-generation transcatheter heart valves (THVs) have been developed to minimize procedural complications and improve patients' outcomes (3).

\section{SEE PAGE 444}

The Acurate neo (NEO) bioprosthesis (developed by Symetis, Ecublens, Switzerland; now Boston Scientific, Marlborough, Massachusetts) is a next-generation self-expanding THV commercially available for TAVR in several countries. Interesting clinical and echocardiographic results have been recently reported after transfemoral TAVR with the NEO valve $(4,5)$, and 2 randomized controlled trials are currently ongoing to compare such device with the SAPIEN 3 and the Evolut R THVs (SCOPE I [Safety and Efficacy of the Symetis Acurate Neo/TF Compared to the Edwards SAPIEN 3 Bioprosthesis; NCT03011346] and SCOPE II [Safety and Efficacy Comparison Of Two TAVI Systems in a Prospective Randomized Evaluation II; NCT03192813], respectively). Recently, the selfexpanding Evolut PRO (PRO) system, the latest generation device in the CoreValve family (Medtronic, Minneapolis, Minnesota), has shown excellent outcomes in the prospective Medtronic Evolut PRO US Clinical Study and has been introduced into clinical practice (6).

To date, no study exists comparing the NEO and latest generation PRO devices; furthermore, the ongoing SCOPE II trial was designed to compare

From the ${ }^{a}$ Interventional Cardiology Unit, San Raffaele Scientific Institute, Milan, Italy; ${ }^{\mathrm{b}}$ Department of Cardiology and Cardiac Surgery, Kerckhoff Heart and Lung Center, Bad Nauheim, Germany; 'Department of Cardiovascular Surgery, University Heart Center, Hamburg, Germany; 'Department of Cardiology, C.A.S.T. Policlinic G. Rodolico Hospital, University of Catania, Catania, Italy; ${ }^{\mathrm{e}}$ Cardio Center, Humanitas Research Hospital, Rozzano-Milan, Italy; ${ }_{\mathrm{f}}^{\mathrm{D}}$ ivision of Cardiology, Pulmonology, and Vascular Medicine, University Hospital Düsseldorf, Düsseldorf, Germany; ${ }^{\mathrm{g}}$ Department of Cardiology, Inselspital, Bern University Hospital, University of Bern, Bern, Switzerland; ${ }^{\mathrm{h}}$ Department for Percutaneous Treatment of Structural Heart Disease, Albertinen Heart Center, Hamburg, Germany; ${ }^{i}$ Division of Cardiology, Medical University of Graz, Graz, Austria; ${ }^{j}$ Department of Cardiology, IRCCS

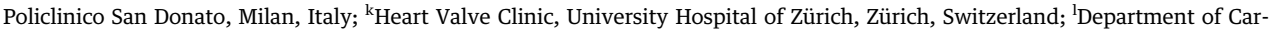
diology, Royal Sussex County Hospital, Brighton, United Kingdom; ${ }^{\mathrm{m}}$ Instituto Dante Pazzanese de Cardiologia, São Paulo, Brazil; ${ }^{\mathrm{n}}$ Contilia Heart and Vascular Centre, Elisabeth-Krankenhaus Essen, Essen, Germany; ${ }^{\circ}$ Department of Cardiology, Thoraxcenter, Erasmus Medical Center, Rotterdam, the Netherlands; ${ }^{\mathrm{D}}$ Department of Medicine II, Heart Center Bonn, University Hospital Bonn, Bonn, Germany; ${ }^{\mathrm{q}}$ Department of Internal Medicine II, University of Ulm, Ulm, Germany; ${ }^{\mathrm{r} H e a r t}$ and Lung Centre, New Cross Hospital, Wolverhampton, United Kingdom; 'separtment of Cardiology, St. Antonius Hospital, Nieuwegein, the Netherlands; ${ }^{t}$ Centre for Heart Valve Innovation, St. Paul's and Vancouver General Hospital, Vancouver, British Columbia, Canada; ${ }^{\text {uDepart- }}$ ment of Cardiology, Hospital of León, León, Spain; ${ }^{\mathrm{v}}$ Department of Cardiology, Galway University Hospitals, Galway, Ireland; wDepartment of Cardiology, King's College Hospital, London, United Kingdom; ${ }^{x}$ Clinic Cardiovascular Institute, University Hospital Clinic, IDIBAPS, Barcelona, Spain; ${ }^{y}$ Department of Cardiology, University Heart Center, Hamburg, Germany; and the ${ }^{z}$ Department of Cardiology, Montefiore Medical Center, Bronx, New York. Dr. Kim is a proctor for Symetis/Boston Scientific and Abbott Vascular; and has received speaking fees from Edwards Lifesciences. Dr. Conradi and Prof. Schäfer are proctors for Symetis/ Boston Scientific and Medtronic, and have received lecture fees and travel support from both companies. Dr. Barbanti has served as a consultant for Edwards Lifesciences. Dr. Stefanini has received a research grant (to the institution) from Boston Scientific; and has received speaking and consulting fees from B. Braun, Biosensors, and Boston Scientific. Dr. Zeus is a proctor for Medtronic; and has received speaker fees and financial scientific support from Medtronic and Edwards Lifesciences. Dr. Pilgrim has received research grants (to the institution) from Boston Scientific, Edwards Lifesciences, and Biotronik; and has received speaking fees from Boston Scientific and Biotronik. Dr. Taramasso is a consultant for Boston Scientific, Abbott Vascular, 4Tech and CoreMedic; and has received speaking fees from Edwards Lifesciences. Dr. Hildick-Smith is an advisor and a proctor for Boston Scientific, Symetis, and Medtronic. Dr. Wolf is a proctor for Medtronic and Boston Scientific. Dr. Van Mieghem has received research grant support from Boston Scientific, Abbott Vascular, Medtronic, Claret, and Essential Medical. Dr. Sedaghat has received travel grants and support from Medtronic. Dr. Khogali is a proctor for Medtronic and Boston Scientific. Prof. Webb is a consultant for Abbott Vascular and Edwards Lifesciences. Dr. Mylotte is a proctor for Medtronic and Microport. Dr. MacCarthy is a proctor for Edwards Lifesciences. Dr. Hamm has served on advisory boards for Medtronic. Prof. Tamburino has received speaking honoraria from Medtronic. Dr. Veulemans has received lecture fees and travel support from Medtronic and Edwards Lifesciences. Prof. Windecker has received grants from Abbott Vascular, Biotronik, Boston Scientific, Edwards Lifesciences, and Medtronic. Dr. Bedogni is a proctor for Medtronic and Boston Scientific. Dr. Maisano has served as a consultant for Edwards Lifesciences, Medtronic, St. Jude Medical, Abbott Vascular, and Valtech; and has received royalties from Edwards Lifesciences. Dr. Siqueira is proctor for Medtronic, Symetis, and Edwards Lifesciences. Dr. Naber has received lecture fees from Boston Scientific, Medtronic, and Abbott Vascular; and has served on advisory boards for Boston Scientific and Abbott Vascular. Prof. Sinning is a proctor for Medtronic and Boston Scientific; and has received speaking honoraria and research grants from Medtronic, Edwards Lifesciences, and Boston Scientific. Prof. Wood has received grant support from Boston Scientific; and is a consultant for Medtronic. Dr. Latib has served on the advisory boards of Medtronic and Abbott Vascular. All other authors have reported that they have no relationships relevant to the contents of this paper to disclose. 
the NEO valve with the second-generation Evolut $\mathrm{R}$ device. Therefore, our aim was to perform a multicenter observational study to compare clinical and echocardiographic outcomes after transfemoral TAVR with the next-generation self-expanding NEO and PRO THVs.

\section{METHODS}

STUDY POPULATION. Our multicenter, observational, retrospective NEOPRO (A Multicenter Comparison of Acurate NEO Versus Evolut PRO Transcatheter Heart Valves) registry included a total of 1,551 patients who underwent transfemoral TAVR with either NEO $(n=1,263)$ or PRO $(n=288)$ devices between January 2012 and March 2018 at 24 centers. The number of patients included from each participating center is detailed in Online Table 1. All consecutive patients treated with transfemoral TAVR for symptomatic, severe aortic stenosis of the native aortic valve (AV) with either NEO or PRO implantation were included in the registry. The treatment period was January 2012 to March 2018 for the NEO device and August 2017 to March 2018 for the PRO device. Local multidisciplinary heart teams evaluated all cases and confirmed eligibility for transfemoral TAVR. All patients provided written informed consent for the procedure and subsequent data collection per local practice for retrospective data.

Pre-procedural screening was performed by means of clinical assessment (patient demographics, symptoms, comorbidities, laboratory examinations, and risk evaluation), echocardiography, and multidetector computed tomography. Native AV and left ventricular outflow tract (LVOT) calcifications were classified and graded using a semiquantitative scoring system, as previously described (7). The selection of prosthesis type and size was at the discretion of the treating physician at each center.

DEVICE DESCRIPTION. The NEO bioprosthesis is implanted using a dedicated transfemoral delivery system inserted through a $20-\mathrm{F}$ sheath, as previously described (8). The device is available in sizes small, medium, and large, which correspond to annular diameters of 23, 25, and $27 \mathrm{~mm}$, respectively. The selfexpanding nitinol frame has porcine pericardial valve leaflets in a supra-annular position, with a pericardial sealing skirt on the outer and inner surface of the stent body.

The PRO bioprosthesis is delivered transfemorally using a dedicated sheathless delivery system with an outer diameter similar to a $16-\mathrm{F}$ sheath. The device has similar properties to the second-generation Evolut R THV (9); the principal design modification is the presence of an external pericardial wrap to enhance annular sealing. The PRO valve is currently available in 23-, 26-, and 29-mm sizes.

STUDY ENDPOINTS. The primary endpoint of the study was post-procedural device success, defined according to Valve Academic Research Consortium-2 (VARC-2) criteria (10). Secondary endpoints of interest were procedural complications and VARC-2defined clinical outcomes at 30 days (including the early safety composite endpoint). Echocardiographic outcomes were evaluated pre-discharge; paravalvular aortic regurgitation (PAR) severity was assessed according to VARC-2 criteria and classified as follows: none or trace, mild, moderate, and severe (10).

STATISTICAL ANALYSIS. Continuous variables are presented as mean \pm SD and were compared using the unpaired Student's $t$-test. Categorical variables are presented as numbers and percentages and were compared using the Fisher exact test (given the high frequency of low proportions).

Propensity score (PS) matching was used to adjust for differences in baseline characteristics and potential confounders that may lead to biased estimates of treatment outcomes $(11,12)$. A PS was calculated for each patient to estimate the propensity toward belonging to a specific treatment group (NEO vs. PRO). This was done by means of a nonparsimonious multivariate logistic regression including the following covariates: age, sex, body mass index, diabetes mellitus, chronic obstructive pulmonary disease, estimated glomerular filtration rate, prior myocardial infarction, peripheral vascular disease, prior cardiac surgery, prior balloon aortic valvuloplasty, previous pacemaker or implantable cardioverter-defibrillator, New York Heart Association functional class III or IV, left ventricular ejection fraction, Society of Thoracic Surgeons Predicted Risk of Mortality score, moderate to heavy AV calcification, and moderate to severe LVOT calcification. The $C$ statistic for the PS model was 0.78 , indicating good discrimination. The HosmerLemeshow goodness-of-fit test p value was 0.35 , confirming good calibration and fit of the multivariate model. A 1-to-1 nearest neighbor matching algorithm without replacement (caliper 0.20) was performed to identify PS-matched pairs. The pseudo- $R^{2}$ value was 0.08 ( $\mathrm{p}<0.0001$ ) before matching and very low (0.007; $\mathrm{p}=0.995)$ after matching, thus confirming the good quality of the match and the adequate balancing of covariate distribution between the matched groups (13).

Pre-specified primary and secondary endpoints were compared between the NEO and PRO groups in both the overall and PS-matched cohorts. In the 
overall cohort, binary logistic regression was also performed to adjust the treatment effect for the PS quintiles. Results of the binary logistic regression are presented as adjusted odds ratio $\left(\mathrm{OR}_{\mathrm{adj}}\right)$ with $95 \%$ confidence interval (CI). The primary endpoint was evaluated in clinically relevant subgroups of the entire population with a post hoc formal interaction testing analysis.

All reported $\mathrm{p}$ values are 2 sided, and a $\mathrm{p}$ value $<0.05$ was considered to indicate statistical significance. All statistical analyses were performed using Stata version 13.0 (STATACorp, College Station, Texas).

\section{RESULTS}

BASELINE PATIENT CHARACTERISTICS. A total of 1,551 patients who underwent transfemoral TAVR with the NEO $(n=1,263)$ or PRO $(n=288)$ THV were included. Baseline characteristics of the entire study population are shown in Table 1. The mean age was $81.8 \pm 5.8$ years, and $35.3 \%$ of patients were men; the mean Society of Thoracic Surgeons Predicted Risk of Mortality score was $5.1 \pm 3.4 \%$. Patients treated with the NEO were more frequently in New York Heart Association functional class III or IV $(77.8 \%$ vs. $66.9 \%$; $\mathrm{p}<0.001)$. Patients treated with the PRO more frequently had peripheral vascular disease (24.3\% vs. $12.4 \%$; p $<0.001)$, history of myocardial infarction (22.7\% vs. $11.5 \%$; p $<0.001)$, and history of previous balloon aortic valvuloplasty (5.3\% vs. $2.4 \%$; $\mathrm{p}=0.017)$. Severity of AV calcification was higher in the PRO group, while degrees of LVOT calcification were similar among the NEO and PRO groups (Table 1).

A 1-to-1 PS matching analysis (for variables summarized in "Methods") resulted in a total of 251 matched pairs. As shown in Table 1, there was no significant difference in any baseline characteristic among the PS-matched NEO and PRO groups, including the degrees of AV and LVOT calcification.

PROCEDURAL CHARACTERISTICS. Procedural characteristics of the entire population are depicted in Table 2. Most patients underwent TAVR under conscious sedation (87.7\%), with a significantly higher rate in the PRO group $(92.3 \%$ vs. $86.7 \%$; $\mathrm{p}=0.007)$. Pre-dilatation and post-dilatation were more frequent in the NEO group (pre-dilatation, $83.3 \%$ vs. $37.1 \%$; post-dilatation, $41.7 \%$ vs. $23.7 \%$; $\mathrm{p}<0.001$ for both). The type of vascular closure technique was different between groups, with ProGlide and Manta used more frequently in the PRO group and Prostar used more frequently in the NEO group $(\mathrm{p}<0.001)$. VARC-2 periprocedural complications were similar between the groups, except for pericardial tamponade that was higher in the NEO group ( $1.6 \%$ vs. $0.0 \%$; p $=0.036)$ Overall, 4 patients had coronary obstruction: 2 patients had coronary obstruction after THV embolization and subsequent valve-in-valve implantation ( 1 in the NEO group and 1 in the PRO group); 1 patient had annular rupture after NEO implantation as a result of post-dilatation, eventually leading to an aorto-right ventricular fistula and right coronary artery obstruction; and 1 patient had cardiac arrest 1 day after NEO implantation with evidence on coronary angiography of left circumflex artery thrombosis.

After PS matching, conscious sedation was similar between the NEO and PRO groups (96.4\% vs. $92.8 \%$; $\mathrm{p}=0.112$ ), while the use of pre-dilatation and post-dilatation remained significantly higher in the NEO group (pre-dilatation, $86.5 \%$ vs. $37.9 \%$; postdilatation, $41.4 \%$ vs. $25.0 \%$; $p<0.001$ for both). There was no significant difference in any peri-procedural complication after PS matching, including pericardial tamponade, second THV implantation, valve embolization, annular rupture, aortic dissection, coronary occlusion, and conversion to open surgery (Table 2). Length of hospital stay was similar between matched NEO and PRO groups ( $\mathrm{p}=0.129)$.

EARLY ECHOCARDIOGRAPHIC OUTCOMES. Early echocardiographic data after TAVR (before discharge) are shown in Table 2. The mean AV gradient was significantly higher after NEO implantation (8.5 \pm $4.0 \mathrm{~mm} \mathrm{Hg}$ vs. $7.2 \pm 3.5 \mathrm{~mm} \mathrm{Hg}$; $>0.001$ ), although the proportion of patients with mean AV gradients $\geq 20 \mathrm{~mm} \mathrm{Hg}$ was similar between groups (1.2\% vs. $1.1 \% ; \mathrm{p}=1.000$ ). As depicted in Figure 1, the overall amount of PAR was higher after NEO implantation ( $\mathrm{p}<0.001$ ), driven by a higher rate of none or trace PAR in the PRO group (52.1\% vs. $37.9 \%)$. The incidence of moderate-to-severe PAR was similar between the PRO and NEO groups (5.7\% vs. 5.2\%; $\mathrm{p}=0.659)$. After adjustment for PS quintiles, the risk for moderate-to-severe PAR remained similar with the PRO and NEO devices $\left(\mathrm{OR}_{\mathrm{adj}}: 0.85 ; 95 \% \mathrm{CI}: 0.46\right.$ to 1.60; $\mathrm{p}=0.625$ ).

In the PS-matched population (Table 2), the mean $\mathrm{AV}$ gradient remained higher after NEO implantation $(8.3 \pm 4.0 \mathrm{~mm} \mathrm{Hg}$ vs. $7.3 \pm 3.6 \mathrm{~mm} \mathrm{Hg} ; \mathrm{p}=0.003)$, with no significant difference in mean $\mathrm{AV}$ gradient $\geq 20 \mathrm{~mm} \mathrm{Hg}$ between matched NEO and PRO pairs (1.2\% vs. $1.3 \%$; $p=1.000)$. The overall amount of PAR was not different between the matched groups ( $\mathrm{p}=0.055)$ (Figure 1$)$, with a similar rate of moderateto-severe PAR after NEO and PRO implantation (7.3\% vs. $5.7 \%$; $\mathrm{p}=0.584$ ). 


\begin{tabular}{|c|c|c|c|c|c|c|c|c|}
\hline & \multicolumn{4}{|c|}{ Entire Population } & \multicolumn{4}{|c|}{ PS-Matched Population } \\
\hline & $\begin{array}{c}\text { Overall } \\
(N=1,551)\end{array}$ & $\begin{array}{l}\text { Acurate neo } \\
(n=1,263)\end{array}$ & $\begin{array}{l}\text { Evolut PRO } \\
(\mathrm{n}=\mathbf{2 8 8})\end{array}$ & p Value & $\begin{array}{c}\text { Overall } \\
(\mathrm{N}=502)\end{array}$ & $\begin{array}{l}\text { Acurate neo } \\
(\mathbf{n}=\mathbf{2 5 1})\end{array}$ & $\begin{array}{c}\text { Evolut PRO } \\
(n=251)\end{array}$ & p Value \\
\hline \multicolumn{9}{|l|}{ Clinical characteristics } \\
\hline Age (yrs) & $\begin{array}{l}81.8 \pm 5.8 \\
(\mathrm{~N}=1,551)\end{array}$ & $\begin{array}{l}81.8 \pm 5.8 \\
(n=1,263)\end{array}$ & $\begin{array}{l}81.7 \pm 5.9 \\
(n=288)\end{array}$ & 0.911 & $\begin{array}{l}81.5 \pm 6.3 \\
(n=502)\end{array}$ & $\begin{array}{l}81.4 \pm 6.5 \\
(n=251)\end{array}$ & $\begin{array}{l}81.6 \pm 6.1 \\
(n=251)\end{array}$ & 0.742 \\
\hline Male & $548 / 1,551(35.3)$ & $444 / 1,263(35.2)$ & $104 / 288(36.1)$ & 0.785 & $172 / 502(34.3)$ & $86 / 251(34.3)$ & $86 / 251(34.3)$ & 1.000 \\
\hline BMI $\left(\mathrm{kg} / \mathrm{m}^{2}\right)$ & $\begin{array}{c}27.4 \pm 5.1 \\
(N=1,479)\end{array}$ & $\begin{array}{l}27.4 \pm 5.1 \\
(n=1,195)\end{array}$ & $\begin{array}{l}27.1 \pm 5.2 \\
(n=284)\end{array}$ & 0.316 & $\begin{array}{l}27.4 \pm 5.3 \\
(n=502)\end{array}$ & $\begin{array}{l}27.7 \pm 5.2 \\
(n=251)\end{array}$ & $\begin{array}{l}27.2 \pm 5.3 \\
(n=251)\end{array}$ & 0.369 \\
\hline COPD & 294/1,548 (19.0) & 244/1,262 (19.3) & $50 / 286(17.5)$ & 0.505 & $92 / 502(18.3)$ & $46 / 251(18.3)$ & $46 / 251(18.3)$ & 1.000 \\
\hline Diabetes mellitus & 455/1,546 (29.4) & $379 / 1,262(30.0)$ & $76 / 284(26.8)$ & 0.281 & $140 / 502$ (27.9) & $72 / 251(28.7)$ & $68 / 251(27.1)$ & 0.765 \\
\hline Hypertension & $1,312 / 1,489(88.1)$ & $1,079 / 1,226(88.0)$ & $233 / 263(88.6)$ & 0.834 & $428 / 424(88.4)$ & $224 / 251(89.2)$ & $204 / 233(87.6)$ & 0.573 \\
\hline Serum creatinine (mg/dl) & $\begin{array}{l}1.18 \pm 0.85 \\
(N=1,546)\end{array}$ & $\begin{array}{l}1.18 \pm 0.86 \\
(n=1,258)\end{array}$ & $\begin{array}{c}1.21 \pm 0.81 \\
(n=288)\end{array}$ & 0.499 & $\begin{array}{c}1.18 \pm 0.72 \\
(n=502)\end{array}$ & $\begin{array}{c}1.17 \pm 0.63 \\
(n=251)\end{array}$ & $\begin{array}{c}1.19 \pm 0.80 \\
(n=251)\end{array}$ & 0.699 \\
\hline eGFR $\left(\mathrm{ml} / \mathrm{min} / 1.73 \mathrm{~m}^{2}\right)$ & $\begin{array}{l}57.9 \pm 21.4 \\
(N=1,546)\end{array}$ & $\begin{array}{l}58.4 \pm 21.7 \\
(n=1,258)\end{array}$ & $\begin{array}{c}55.7 \pm 20.2 \\
(n=288)\end{array}$ & 0.052 & $\begin{array}{c}56.6 \pm 20.7 \\
(n=502)\end{array}$ & $\begin{array}{c}57.2 \pm 21.4 \\
(n=251)\end{array}$ & $\begin{array}{c}56.2 \pm 20.1 \\
(n=251)\end{array}$ & 0.609 \\
\hline eGFR $<30 \mathrm{ml} / \mathrm{min} / 1.73 \mathrm{~m}^{2}$ & $141 / 1,546(9.1)$ & $113 / 1,258(9.0)$ & $28 / 288(9.7)$ & 0.733 & $46 / 502(9.2)$ & $23 / 251(9.2)$ & $23 / 251(9.2)$ & 1.000 \\
\hline Dialysis & $30 / 1,548(1.9)$ & $22 / 1,262(1.7)$ & $8 / 286(2.8)$ & 0.238 & $11 / 502(2.2)$ & $4 / 251(1.6)$ & $7 / 251(2.8)$ & 0.544 \\
\hline Prior MI & 203/1,491 (13.6) & $138 / 1,205(11.5)$ & $65 / 286(22.7)$ & $<0.001$ & $109 / 502(21.7)$ & $52 / 251(20.7)$ & $57 / 251(22.7)$ & 0.665 \\
\hline $\begin{array}{c}\text { Prior cardiac surgery } \\
\text { (CABG or MV } \\
\text { intervention) }\end{array}$ & $178 / 1,549(11.5)$ & $154 / 1,263(12.2)$ & $24 / 286(8.4)$ & 0.080 & $41 / 502(8.2)$ & $21 / 251(8.4)$ & $20 / 251(8.0)$ & 1.000 \\
\hline Prior CABG & $169 / 1,549$ (10.9) & $147 / 1,263(11.6)$ & $22 / 286(7.7)$ & 0.058 & $39 / 502(7.8)$ & $20 / 251(8.0)$ & 19/251 (7.6) & 0.868 \\
\hline Prior MV surgery & $9 / 1,549(0.6)$ & $7 / 1,263(0.6)$ & $2 / 286(0.7)$ & 0.675 & $2 / 502(0.4)$ & $1 / 251(0.4)$ & $1 / 251(0.4)$ & 1.000 \\
\hline Prior BAV & $41 / 1,387$ (3.0) & $26 / 1,102(2.4)$ & $15 / 285(5.3)$ & 0.017 & $17 / 502(3.4)$ & $6 / 251(2.4)$ & $11 / 251(4.4)$ & 0.324 \\
\hline Peripheral vascular disease & $225 / 1,546(14.6)$ & $156 / 1,262(12.4)$ & $69 / 284(24.3)$ & $<0.001$ & $124 / 502(24.7)$ & $62 / 251(24.7)$ & $62 / 251(24.7)$ & 1.000 \\
\hline Prior stroke & $148 / 1,512(9.8)$ & $126 / 1,226(10.3)$ & $22 / 286(7.7)$ & 0.224 & $44 / 502(8.8)$ & $25 / 251(10.0)$ & 19/251 (7.6) & 0.430 \\
\hline Atrial fibrillation/flutter & $506 / 1,539$ (32.9) & $408 / 1,253(32.6)$ & $98 / 286(34.3)$ & 0.578 & $184 / 502(36.7)$ & $93 / 251(37.1)$ & $91 / 251(36.3)$ & 0.926 \\
\hline PM or ICD & 184/1,550 (11.9) & $158 / 1,262(12.5)$ & $26 / 288(9.0)$ & 0.106 & $44 / 502(8.8)$ & $21 / 251(8.4)$ & 23/251 (9.2) & 0.875 \\
\hline NYHA functional class III or IV & $1,173 / 1,548(75.8)$ & $981 / 1,261(77.8)$ & 192/287 (66.9) & $<0.001$ & $344 / 502(68.5)$ & $175 / 251(69.7)$ & $169 / 251(67.3)$ & 0.631 \\
\hline STS-M (\%) & $\begin{array}{l}5.08 \pm 3.37 \\
(\mathrm{~N}=1,446)\end{array}$ & $\begin{array}{c}5.02 \pm 3.23 \\
(n=1,160)\end{array}$ & $\begin{array}{c}5.35 \pm 3.87 \\
(n=286)\end{array}$ & 0.137 & $\begin{array}{c}5.17 \pm 3.40 \\
(n=502)\end{array}$ & $\begin{array}{c}5.08 \pm 3.05 \\
(n=251)\end{array}$ & $\begin{array}{c}5.25 \pm 3.72 \\
(n=251)\end{array}$ & 0.577 \\
\hline EuroSCORE II (\%) & $\begin{array}{l}6.17 \pm 6.03 \\
(N=1,383)\end{array}$ & $\begin{array}{l}6.23 \pm 5.99 \\
(n=1,109)\end{array}$ & $\begin{array}{c}5.96 \pm 6.22 \\
(n=274)\end{array}$ & 0.510 & $\begin{array}{c}6.05 \pm 5.62 \\
(n=473)\end{array}$ & $\begin{array}{c}6.34 \pm 5.21 \\
(n=228)\end{array}$ & $\begin{array}{c}5.78 \pm 5.97 \\
(n=245)\end{array}$ & 0.279 \\
\hline \multicolumn{9}{|l|}{ Echocardiographic data } \\
\hline Mean AV gradient (mm Hg) & $\begin{array}{l}43.4 \pm 16.6 \\
(N=1,501)\end{array}$ & $\begin{array}{l}43.5 \pm 16.7 \\
(n=1,221)\end{array}$ & $\begin{array}{l}43.2 \pm 16.5 \\
(n=280)\end{array}$ & 0.833 & $\begin{array}{c}44.5 \pm 16.4 \\
(n=493)\end{array}$ & $\begin{array}{c}45.7 \pm 16.1 \\
(n=247)\end{array}$ & $\begin{array}{c}43.2 \pm 16.6 \\
(n=246)\end{array}$ & 0.084 \\
\hline $\begin{array}{l}\text { Maximum AV gradient } \\
\qquad(\mathrm{mm} \mathrm{Hg})\end{array}$ & $\begin{array}{c}69.9 \pm 24.9 \\
(N=1,474)\end{array}$ & $\begin{array}{c}69.8 \pm 25.0 \\
(n=1,201)\end{array}$ & $\begin{array}{c}70.3 \pm 24.5 \\
(n=273)\end{array}$ & 0.758 & $\begin{array}{c}71.7 \pm 24.5 \\
(n=482)\end{array}$ & $\begin{array}{c}73.1 \pm 24.5 \\
(n=243)\end{array}$ & $\begin{array}{c}70.1 \pm 24.5 \\
(n=239)\end{array}$ & 0.181 \\
\hline AVA $\left(\mathrm{cm}^{2}\right)$ & $\begin{array}{l}0.71 \pm 0.19 \\
(N=1,450)\end{array}$ & $\begin{array}{c}0.71 \pm 0.19 \\
(n=1,172)\end{array}$ & $\begin{array}{c}0.71 \pm 0.20 \\
(n=278)\end{array}$ & 0.834 & $\begin{array}{c}0.70 \pm 0.20 \\
(n=480)\end{array}$ & $\begin{array}{c}0.68 \pm 0.17 \\
(n=234)\end{array}$ & $\begin{array}{c}0.71 \pm 0.20 \\
(n=246)\end{array}$ & 0.083 \\
\hline Moderate to severe AR & $213 / 1,507(14.1)$ & $177 / 1,227(14.4)$ & $36 / 280$ (12.9) & 0.568 & $71 / 495(14.3)$ & $41 / 249(16.5)$ & $30 / 246(12.2)$ & 0.200 \\
\hline $\operatorname{LVEF}(\%)$ & $\begin{array}{l}56.7 \pm 11.7 \\
(N=1,526)\end{array}$ & $\begin{array}{l}56.8 \pm 11.8 \\
(n=1,245)\end{array}$ & $\begin{array}{c}56.3 \pm 11.6 \\
(n=281)\end{array}$ & 0.549 & $\begin{array}{l}56.5 \pm 11.7 \\
(n=502)\end{array}$ & $\begin{array}{c}56.5 \pm 11.6 \\
(n=251)\end{array}$ & $\begin{array}{c}56.5 \pm 11.7 \\
(n=251)\end{array}$ & 0.957 \\
\hline $\begin{array}{l}\text { Severe pulmonary } \\
\text { hypertension* }\end{array}$ & $214 / 1,261(17.0)$ & $169 / 976(17.3)$ & $45 / 285(15.8)$ & 0.591 & $77 / 463$ (16.6) & $36 / 214(16.8)$ & $41 / 249(16.5)$ & 1.000 \\
\hline Moderate to severe MR & $357 / 1,504(23.7)$ & $282 / 1,226(23.0)$ & $75 / 278(27.0)$ & 0.161 & $132 / 492(26.8)$ & $72 / 247(29.2)$ & $60 / 245(24.5)$ & 0.264 \\
\hline Moderate to severe TR & 263/1,489 (17.7) & 209/1,215 (17.2) & $54 / 274(19.7)$ & 0.335 & 93/489 (19.0) & $45 / 247(18.2)$ & 48/242 (19.8) & 0.730 \\
\hline \multicolumn{9}{|l|}{ MDCT } \\
\hline AV calcification & & & & $<0.001$ & & & & 0.313 \\
\hline None & $5 / 1,243(0.4)$ & 4/977 (0.4) & $1 / 266(0.4)$ & & $2 / 502(0.4)$ & $1 / 251(0.4)$ & $1 / 251(0.4)$ & \\
\hline Mild & $323 / 1,243(26.0)$ & 282/977 (28.9) & $41 / 266(15.4)$ & & $76 / 502(15.1)$ & $37 / 251(14.7)$ & $39 / 251(15.5)$ & \\
\hline Moderate & $545 / 1,243$ (43.9) & $428 / 977(43.8)$ & $117 / 266$ (44.0) & & $241 / 502$ (48.0) & $130 / 251(51.8)$ & $111 / 251(44.2)$ & \\
\hline Heavy & $370 / 1,243(29.8)$ & 263/977 (26.9) & $107 / 266(40.2)$ & & $183 / 502(36.5)$ & $83 / 251(33.1)$ & $100 / 251(39.8)$ & \\
\hline LVOT calcification & & & & 0.229 & & & & 0.206 \\
\hline None & $682 / 1,246(54.7)$ & $541 / 975(55.5)$ & $141 / 271(52.0)$ & & $243 / 502(48.4)$ & $113 / 251(45.0)$ & $130 / 251(51.8)$ & \\
\hline Mild & $337 / 1,246(27.0)$ & $265 / 975(27.2)$ & $72 / 271(26.6)$ & & $139 / 502(27.7)$ & $72 / 251(28.7)$ & $67 / 251(26.7)$ & \\
\hline Moderate & $138 / 1,246(11.1)$ & 107/975 (11.0) & $31 / 271(11.4)$ & & $75 / 502$ (14.9) & 45/251 (17.9) & $30 / 251(12.0)$ & \\
\hline Severe & $89 / 1,246(7.1)$ & $62 / 975(6.4)$ & $27 / 271(10.0)$ & & $45 / 502(9.0)$ & $21 / 251(8.4)$ & $24 / 251(9.6)$ & \\
\hline
\end{tabular}

Values are mean $\pm \mathrm{SD}$ or $\mathrm{n} / \mathrm{N}(\%)$. *Systolic pulmonary artery pressure on echocardiography $>55 \mathrm{~mm} \mathrm{Hg}$.

$A R=$ aortic regurgitation; $A V=$ aortic valve; $A V A=$ aortic valve area; $B A V=$ balloon aortic valvuloplasty; $B M I=$ body mass index; $C A B G=$ coronary artery bypass graft; COPD = chronic obstructive pulmonary disease; eGFR = estimated glomerular filtration rate; EuroSCORE $=$ European System for Cardiac Operative Risk Evaluation; ICD = implantable cardioverter-defibrillator; LVEF = left ventricular ejection fraction; LVOT = left ventricular outflow tract; MDCT = multidetector computed tomography; $\mathrm{MI}=$ myocardial infarction; $\mathrm{MR}=$ mitral regurgitation; $\mathrm{MV}=$ mitral valve; $\mathrm{NYHA}=\mathrm{New}$ York Heart Association; $\mathrm{PCl}$ = percutaneous coronary intervention; PM = pacemaker; PS = propensity score; STS-M = Society of Thoracic Surgeons Predicted Risk of Mortality; TR = tricuspid regurgitation. 


\begin{tabular}{|c|c|c|c|c|c|c|c|c|}
\hline & \multicolumn{4}{|c|}{ Entire Population } & \multicolumn{4}{|c|}{ PS-Matched Population } \\
\hline & $\begin{array}{c}\text { Overall } \\
(\mathrm{N}=1,551)\end{array}$ & $\begin{array}{l}\text { Acurate neo } \\
(n=1,263)\end{array}$ & $\begin{array}{c}\text { Evolut PRO } \\
(\mathrm{n}=\mathbf{2 8 8})\end{array}$ & p Value & $\begin{array}{c}\text { Overall } \\
(\mathrm{N}=502)\end{array}$ & $\begin{array}{c}\text { Acurate neo } \\
(\mathbf{n}=251)\end{array}$ & $\begin{array}{c}\text { Evolut PRO } \\
(\mathbf{n}=\mathbf{2 5 1})\end{array}$ & p Value \\
\hline \multicolumn{9}{|l|}{ Procedural characteristics } \\
\hline Conscious sedation & $1,359 / 1,549(87.7)$ & $1,094 / 1,262(86.7)$ & 265/287 (92.3) & 0.007 & $475 / 502(94.6)$ & $242 / 251(96.4)$ & $233 / 251(92.8)$ & 0.112 \\
\hline \multicolumn{9}{|l|}{ Valve size } \\
\hline Small & - & $348 / 1,262(27.6)$ & - & & - & 60/251 (23.9) & - & \\
\hline Medium & - & $520 / 1,262(41.2)$ & - & & - & 105/251 (41.8) & - & \\
\hline Large & - & $394 / 1,262(31.2)$ & - & & - & $86 / 251(34.3)$ & - & \\
\hline $23 \mathrm{~mm}$ & - & - & $7 / 288(2.4)$ & & - & - & $5 / 251(2.0)$ & \\
\hline $26 \mathrm{~mm}$ & - & - & $108 / 288(37.5)$ & & - & - & 96/251 (38.3) & \\
\hline $29 \mathrm{~mm}$ & - & - & $173 / 288(60.1)$ & & - & - & $150 / 251(59.8)$ & \\
\hline Pre-dilatation & $1,156 / 1,545(74.8)$ & $1,051 / 1,262(83.3)$ & 105/283 (37.1) & $<0.001$ & $311 / 499(62.3)$ & 217/251 (86.5) & $94 / 248(37.9)$ & $<0.001$ \\
\hline Post-dilatation & $593 / 1,544(38.4)$ & $526 / 1,261(41.7)$ & $67 / 283(23.7)$ & $<0.001$ & 166/499 (33.3) & $104 / 251(41.4)$ & $62 / 248(25.0)$ & $<0.001$ \\
\hline Vascular closure technique & & & & $<0.001$ & & & & $<0.001$ \\
\hline ProGlide & $946 / 1,550(61.0)$ & $717 / 1,262(56.8)$ & 229/288 (79.5) & & $344 / 502(68.5)$ & 138/251 (54.5) & 206/251 (82.1) & \\
\hline Prostar & $555 / 1,550(35.8)$ & $525 / 1,262(41.6)$ & $30 / 288(10.4)$ & & $129 / 502(25.7)$ & $108 / 251(43.0)$ & $21 / 251(8.4)$ & \\
\hline Manta & $47 / 1,550(3.0)$ & $19 / 1,262(1.5)$ & $28 / 288(9.7)$ & & $28 / 502(5.6)$ & $5 / 251(2.0)$ & $23 / 251(9.2)$ & \\
\hline Surgical closure & $2 / 1,550(0.1)$ & $1 / 1,262(0.1)$ & $1 / 288(0.4)$ & & $1 / 502(0.2)$ & $0 / 251(0.0)$ & $1 / 251(0.4)$ & \\
\hline Valve repositioning & - & - & 21/264 (8.0) & - & - & - & 20/233 (8.6) & - \\
\hline Second THV implanted & 20/1,551 (1.3) & $14 / 1,263(1.1)$ & $6 / 288(2.1)$ & 0.240 & $5 / 502(1.0)$ & $2 / 251(0.8)$ & $3 / 251(1.2)$ & 1.000 \\
\hline Valve embolization & 16/1,551 (1.0) & $13 / 1,263(1.0)$ & $3 / 288(1.0)$ & 1.000 & $3 / 502(0.6)$ & $1 / 251(0.4)$ & $2 / 251(0.8)$ & 1.000 \\
\hline Annular rupture & $4 / 1,551(0.3)$ & $4 / 1,263(0.3)$ & $0 / 288(0.0)$ & 1.000 & 0/502 (0.0) & $0 / 251(0.0)$ & $0 / 251(0.0)$ & - \\
\hline Pericardial tamponade & 20/1,551 (1.3) & $20 / 1,263(1.6)$ & $0 / 288(0.0)$ & 0.036 & $5 / 502(1.0)$ & $5 / 251(2.0)$ & $0 / 251(0.0)$ & 0.061 \\
\hline Aortic dissection & $1 / 1,551(0.1)$ & $1 / 1,263(0.1)$ & $0 / 288(0.0)$ & 1.000 & 0/502 (0.0) & $0 / 251(0.0)$ & $0 / 251(0.0)$ & - \\
\hline Coronary occlusion & $3 / 1,551(0.2)$ & $2 / 1,263(0.2)$ & $1 / 288(0.4)$ & 0.460 & $0 / 502(0.0)$ & $0 / 251(0.0)$ & $0 / 251(0.0)$ & - \\
\hline Conversion to surgery & $13 / 1,551(0.8)$ & $13 / 1,263(1.0)$ & $0 / 288(0.0)$ & 0.144 & $2 / 502(0.4)$ & $2 / 251(0.8)$ & $0 / 251(0.0)$ & 0.499 \\
\hline Length of hospital stay (days) & $\begin{array}{c}8.1 \pm 6.2 \\
(N=1,453)\end{array}$ & $\begin{array}{l}8.3 \pm 5.9 \\
(n=1,168)\end{array}$ & $\begin{array}{l}7.5 \pm 7.2 \\
(n=285)\end{array}$ & 0.050 & $\begin{array}{l}8.1 \pm 6.8 \\
(n=494)\end{array}$ & $\begin{array}{l}8.5 \pm 5.9 \\
(n=245)\end{array}$ & $\begin{array}{l}7.6 \pm 7.5 \\
(n=249)\end{array}$ & 0.129 \\
\hline \multicolumn{9}{|l|}{$\begin{array}{l}\text { Pre-discharge echocardiographic } \\
\text { outcomes }\end{array}$} \\
\hline Mean AV gradient (mm Hg) & $\begin{array}{c}8.3 \pm 4.0 \\
(N=1,416)\end{array}$ & $\begin{array}{l}8.5 \pm 4.0 \\
(n=1,145)\end{array}$ & $\begin{array}{l}7.2 \pm 3.5 \\
(n=271)\end{array}$ & $<0.001$ & $\begin{array}{l}7.8 \pm 3.8 \\
(n=483)\end{array}$ & $\begin{array}{l}8.3 \pm 4.0 \\
(n=245)\end{array}$ & $\begin{array}{l}7.3 \pm 3.6 \\
(n=238)\end{array}$ & 0.003 \\
\hline Mean $\mathrm{AV}$ gradient $\geq 20 \mathrm{~mm} \mathrm{Hg}$ & $17 / 1,416(1.2)$ & $14 / 1,145(1.2)$ & $3 / 271(1.1)$ & 1.000 & $6 / 483(1.2)$ & $3 / 245(1.2)$ & $3 / 238(1.3)$ & 1.000 \\
\hline Moderate to severe total AR & $84 / 1,481(5.7)$ & $68 / 1,201(5.7)$ & $16 / 280(5.7)$ & 1.000 & $32 / 492(6.5)$ & $18 / 247(7.3)$ & $14 / 245(5.7)$ & 0.584 \\
\hline Moderate to severe paravalvular AR & $78 / 1,481(5.3)$ & $62 / 1,201(5.2)$ & $16 / 280(5.7)$ & 0.659 & $32 / 492(6.5)$ & $18 / 247(7.3)$ & $14 / 245(5.7)$ & 0.584 \\
\hline LVEF (\%) & $\begin{array}{l}58.6 \pm 10.2 \\
(N=1,196)\end{array}$ & $\begin{array}{l}58.7 \pm 10.2 \\
(n=940)\end{array}$ & $\begin{array}{l}58.1 \pm 10.2 \\
(n=256)\end{array}$ & 0.439 & $\begin{array}{l}58.5 \pm 9.7 \\
(n=454)\end{array}$ & $\begin{array}{l}58.6 \pm 9.1 \\
(n=224)\end{array}$ & $\begin{array}{l}58.4 \pm 10.4 \\
(n=230)\end{array}$ & 0.826 \\
\hline VARC-2 device success & $1,297 / 1,414(91.7)$ & $1,052 / 1,144(92.0)$ & $245 / 270(90.7)$ & 0.539 & 439/482 (91.1) & 222/245 (90.6) & 217/237 (91.6) & 0.751 \\
\hline
\end{tabular}

VARC-2 DEVICE SUCCESS AND 30-DAY CLINICAL OUTCOMES. Device success was $91.7 \%$, with a similar rate between the NEO and PRO groups (92.0\% vs. $90.7 \% ; p=0.539$ ). Information on 30-day survival status was available for 1,544 of 1,551 patients (99.5\%), with 43 deaths in the 30 -day period after TAVR (all-cause mortality rate $2.8 \%$ ); the remaining 7 patients were lost to follow-up. As shown in Table 3, in the entire population there were no significant differences in all-cause mortality $(3.0 \%$ vs. $1.8 \%$; $\mathrm{p}=0.319)$ and cardiovascular mortality (2.3\% vs. $1.1 \%$; $\mathrm{p}=0.249$ ) at 30 days. Rates of hospitalization for valve-related symptoms or worsening congestive heart failure, any stroke, disabling stroke, myocardial infarction, acute kidney injury stage 2 or 3, coronary obstruction, valve embolization or migration, endocarditis, THV thrombosis, and valve dysfunction requiring repeat procedure did not differ between the NEO and PRO groups (Table 3). TAVR with NEO was associated with a higher rate of any bleeding (14.9\% vs. $8.5 \% ; \mathrm{p}=0.004)$ and any vascular complication $(8.1 \%$ vs. $4.6 \%$; $p=0.025)$, with no significant differences in life-threatening bleeding, major bleeding, and major vascular complications between the NEO and PRO groups. The unadjusted rate of new permanent pacemaker implantation (PPI) was higher with 
FIGURE 1 Paravalvular Aortic Regurgitation After Transcatheter Aortic Valve Replacement
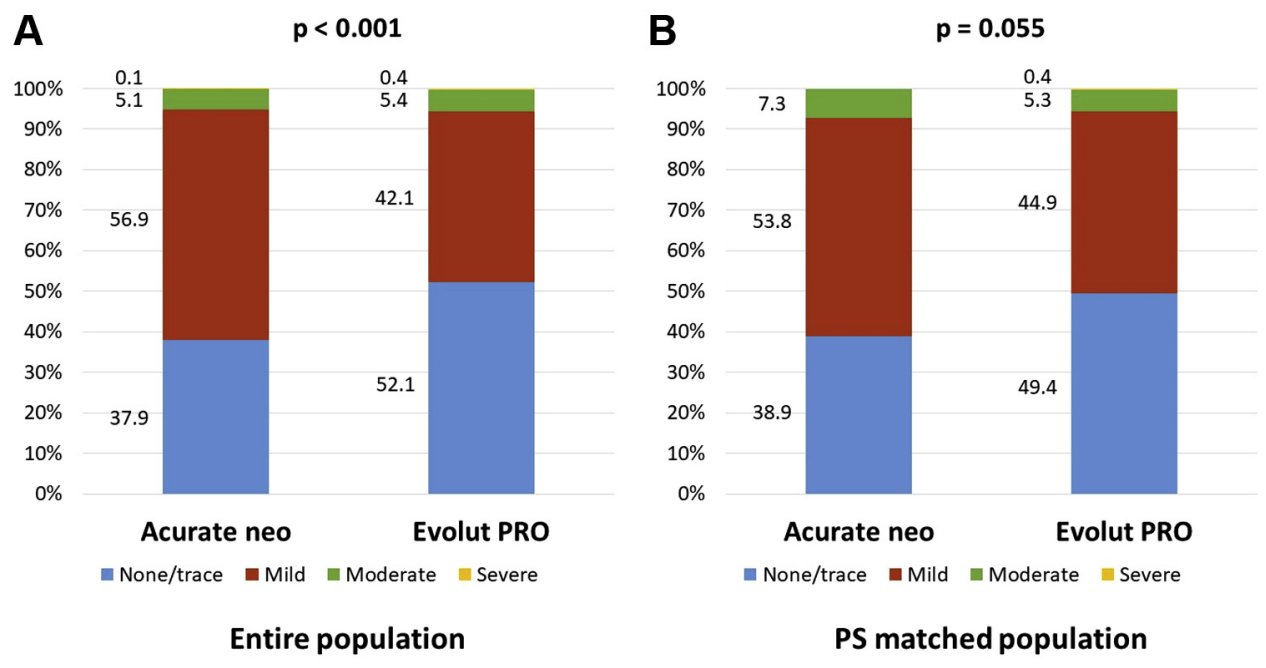

Grades of paravalvular aortic regurgitation after transcatheter aortic valve replacement (TAVR) are presented for both the entire population (A) and the propensity score (PS)-matched cohort (B).

the PRO compared with the NEO (13.2\% vs. 8.8\%; $\mathrm{p}=0.045)$. The VARC-2 safety composite endpoint at 30 days (all-cause mortality, any stroke, lifethreatening bleeding, acute kidney injury stage 2 or 3 , coronary obstruction, major vascular complications, or valve dysfunction requiring repeat procedure) was higher in the NEO group (16.4\% vs. $10.9 \%$; $\mathrm{p}=0.025$ ).

After adjustment for PS quintiles, VARC-2 device success was similar with the PRO and NEO devices $\left(\mathrm{OR}_{\mathrm{adj}}\right.$ : $1.15 ; 95 \% \mathrm{CI}$ : 0.68 to $\left.1.96 ; \mathrm{p}=0.598\right)$. Similarly, the implanted valve did not have a significant impact on all-cause mortality $\left(\mathrm{OR}_{\mathrm{adj}}\right.$ : 0.42; $95 \% \mathrm{CI}: 0.12$ to $1.43 ; \mathrm{p}=0.166)$, cardiovascular mortality $\left(\mathrm{OR}_{\mathrm{adj}}: 0.19\right.$; 95\% CI: 0.02 to $1.42 ; \mathrm{p}=0.104$ ), hospitalization for valve-related symptoms or worsening congestive heart failure $\left(\mathrm{OR}_{\mathrm{adj}}: 2.21 ; 95 \% \mathrm{CI}: 0.80\right.$ to 6.11 ; $\mathrm{p}=0.126)$, any stroke $\left(\mathrm{OR}_{\mathrm{adj}}: 1.15 ; 95 \% \mathrm{CI}: 0.47\right.$ to 2.82; $\mathrm{p}=0.758)$, any bleeding $\left(\mathrm{OR}_{\mathrm{adj}}: 0.63 ; 95 \% \mathrm{CI}\right.$ : 0.38 to $1.03 ; \mathrm{p}=0.067)$, any vascular complication $\left(\mathrm{OR}_{\mathrm{adj}}\right.$ : 0.75; 95\% CI: 0.48 to $\left.1.16 ; \mathrm{p}=0.196\right)$, new PPI $\left(\mathrm{OR}_{\mathrm{adj}}: 1.49 ; 95 \% \mathrm{CI}: 0.93\right.$ to $\left.2.39 ; \mathrm{p}=0.100\right)$, and VARC-2 early safety composite endpoint $\left(\mathrm{OR}_{\mathrm{adj}}\right.$ : 0.76; 95\% CI: 0.48 to $1.20 ; \mathrm{p}=0.234$ ) at 30 days.

No significant interactions between implanted valve and relevant subgroups with respect to VARC-2 device success were observed in the overall population (Online Figure 1).

In the PS-matched population, VARC-2 device success was similar between the NEO and PRO groups (90.6\% vs. $91.6 \% ; \mathrm{p}=0.751)$. There were no significant differences in any other 30-day clinical outcome between matched NEO and PRO pairs (Table 3), including all-cause mortality (3.2\% vs. $1.2 \%$; $\mathrm{p}=0.221)$, cardiovascular mortality (2.4\% vs. $0.4 \%$; $\mathrm{p}=0.122)$, any stroke ( $2.4 \%$ vs. $2.8 \% ; \mathrm{p}=1.000$ ), any bleeding (13.0\% vs. $8.4 \%$; p = 0.112), any vascular complication (14.2\% vs. $11.7 \%$; p $=0.424)$, new PPI (11.0\% vs. $12.8 \%$; $\mathrm{p}=0.565)$, and VARC-2 early safety composite endpoint (10.6\% vs. 10.4\%; $\mathrm{p}=1.000$ ).

\section{DISCUSSION}

Our multicenter study represents the first comparison of transfemoral TAVR with the next-generation selfexpanding NEO and PRO devices in a total of 1,551 patients. The main findings of our registry are as follows. 1) VARC-2 device success was obtained in 91.7\% of patients, with similar rates after NEO and PRO implantation in the entire population, after adjustment for PS quintiles, and in the PS-matched cohort. 2) The rate of moderate to severe PAR after TAVR was acceptable (5.3\%), with no difference between the NEO and PRO groups in the entire population, after adjustment for PS quintiles, and in the PS-matched cohort. 3) In the overall population, the rate of new PPI was higher after PRO implantation (13.2\% vs. $8.8 \%$ ), and the VARC-2 early safety composite endpoint was higher after NEO implantation (16.4\% vs. $10.9 \%)$; however, there was no difference in any 30-day clinical endpoint after adjustment for PS quintiles and in the PS-matched groups. 


\begin{tabular}{|c|c|c|c|c|c|c|c|c|}
\hline & \multicolumn{4}{|c|}{ Entire Population } & \multicolumn{4}{|c|}{ PS-Matched Population } \\
\hline & $\begin{array}{c}\text { Overall } \\
(\mathrm{N}=1,551)\end{array}$ & $\begin{array}{l}\text { Acurate neo } \\
(n=1,263)\end{array}$ & $\begin{array}{l}\text { Evolut PRO } \\
(\mathrm{n}=\mathbf{2 8 8})\end{array}$ & p Value & $\begin{array}{l}\text { Overall } \\
(\mathrm{N}=502)\end{array}$ & $\begin{array}{l}\text { Acurate neo } \\
(\mathrm{n}=\mathbf{2 5 1})\end{array}$ & $\begin{array}{l}\text { Evolut PRO } \\
(\mathrm{n}=251)\end{array}$ & p Value \\
\hline All-cause mortality & $43 / 1,544(2.8)$ & $38 / 1,258(3.0)$ & $5 / 286(1.8)$ & 0.319 & $11 / 501(2.2)$ & $8 / 251(3.2)$ & $3 / 250(1.2)$ & 0.221 \\
\hline Cardiovascular mortality & $32 / 1,544(2.1)$ & 29/1,258 (2.3) & $3 / 286(1.1)$ & 0.249 & $7 / 501(1.4)$ & $6 / 251(2.4)$ & 1/250 (0.4) & 0.122 \\
\hline $\begin{array}{l}\text { Hospitalization for valve-related } \\
\text { symptoms or worsening CHF }\end{array}$ & $19 / 1,300(1.5)$ & $12 / 1,016(1.2)$ & $7 / 284(2.5)$ & 0.156 & 10/494 (2.0) & $3 / 245(1.2)$ & $7 / 249(2.8)$ & 0.339 \\
\hline Any stroke & $39 / 1,529(2.1)$ & $25 / 1,245(2.0)$ & $7 / 284(2.5)$ & 0.645 & 13/496 (2.6) & $6 / 247(2.4)$ & $7 / 249(2.8)$ & 1.000 \\
\hline Disabling stroke & 24/1,529 (1.6) & 20/1,245 (1.6) & $4 / 284(1.4)$ & 1.000 & $9 / 496(1.8)$ & $5 / 247(2.0)$ & 4/249 (1.6) & 0.751 \\
\hline MI & $8 / 1,476(0.5)$ & 7/1,192 (0.6) & $1 / 284(0.4)$ & 1.000 & 2/499 (0.4) & $1 / 250(0.4)$ & $1 / 249(0.4)$ & 1.000 \\
\hline Any bleeding & 201/1,472 (13.7) & 177/1,188 (14.9) & $24 / 284(8.5)$ & 0.004 & 53/496 (10.7) & 32/247 (13.0) & 21/249 (8.4) & 0.112 \\
\hline Life-threatening & 28/1,472 (1.9) & $25 / 1,188(2.1)$ & $3 / 284(1.1)$ & 0.335 & $8 / 496(1.6)$ & $6 / 247(2.4)$ & 2/249 (0.8) & 0.175 \\
\hline Major & $64 / 1,472(4.4)$ & $56 / 1,188(4.7)$ & $8 / 284(2.8)$ & 0.195 & $16 / 496(3.2)$ & $10 / 247(4.1)$ & $6 / 249(2.4)$ & 0.323 \\
\hline Minor & $109 / 1,472(7.4)$ & $96 / 1,188(8.1)$ & $13 / 284(4.6)$ & 0.044 & 29/496 (5.9) & $16 / 247(6.5)$ & $13 / 249(5.2)$ & 0.572 \\
\hline Any vascular complication & $246 / 1,529(16.1)$ & 213/1,245 (17.1) & $33 / 284(11.6)$ & 0.025 & 64/496 (12.9) & $35 / 247(14.2)$ & 29/249 (11.7) & 0.424 \\
\hline Major & $85 / 1,529(5.6)$ & $75 / 1,245(6.0)$ & 10/284 (3.5) & 0.114 & 20/496 (4.0) & $12 / 247(4.9)$ & $8 / 249(3.2)$ & 0.372 \\
\hline Minor & 161/1,529 (10.5) & 138/1,245 (11.1) & 23/284 (8.1) & 0.163 & 44/496 (8.9) & 23/247 (9.3) & 21/249 (8.4) & 0.754 \\
\hline AKI stage 2 or 3 & $43 / 1,469(2.9)$ & $37 / 1,185(3.1)$ & $6 / 284(2.1)$ & 0.438 & 10/495 (2.0) & $6 / 246(2.4)$ & $4 / 249(1.6)$ & 0.543 \\
\hline Coronary obstruction & $4 / 1,530(0.3)$ & $3 / 1,245(0.2)$ & $1 / 285(0.4)$ & 0.562 & 0/496 (0.0) & $0 / 247(0.0)$ & 0/249 (0.0) & - \\
\hline Valve embolization or migration & $17 / 1,532(1.1)$ & $14 / 1,247(1.1)$ & $3 / 285(1.1)$ & 1.000 & 3/497 (0.6) & $1 / 247(0.4)$ & $2 / 250(0.8)$ & 1.000 \\
\hline Endocarditis & $1 / 1,370(0.1)$ & $1 / 1,086(0.1)$ & $0 / 284(0.0)$ & 1.000 & 0/496 (0.0) & $0 / 247(0.0)$ & 0/249 (0.0) & - \\
\hline THV thrombosis & $0 / 1,300(0.0)$ & $0 / 1,016(0.0)$ & 0/284 (0.0) & - & 0/480 (0.0) & $0 / 231(0.0)$ & $0 / 249(0.0)$ & - \\
\hline $\begin{array}{l}\text { Valve dysfunction requiring repeat } \\
\text { procedure (BAV, TAVR, or SAVR) }\end{array}$ & $5 / 1,370(0.4)$ & $3 / 1,086(0.3)$ & $2 / 284(0.7)$ & 0.278 & 2/496 (0.4) & $0 / 247(0.0)$ & $2 / 249(0.8)$ & 0.499 \\
\hline $\begin{array}{l}\text { New permanent pacemaker } \\
\text { implantation* }\end{array}$ & $130 / 1,347$ (9.7) & $96 / 1,089(8.8)$ & $34 / 258(13.2)$ & 0.045 & $54 / 453$ (11.9) & 25/227 (11.0) & 29/226 (12.8) & 0.565 \\
\hline $\begin{array}{l}\text { VARC-2 early safety composite } \\
\text { endpoint }\end{array}$ & 204/1,342 (15.2) & 173/1,058 (16.4) & 31/284 (10.9) & 0.025 & 52/495 (10.5) & 26/246 (10.6) & $26 / 249(10.4)$ & 1.000 \\
\hline
\end{tabular}

Values are $\mathrm{n} / \mathrm{N}$ (\%). *Excluding patients with pacemaker at baseline.

$\mathrm{AKI}=$ acute kidney injury; $\mathrm{BAV}=$ balloon aortic valvuloplasty; $\mathrm{CHF}=$ congestive heart failure; SAVR $=$ surgical aortic valve replacement; $\mathrm{TAVR}=$ transcatheter aortic valve replacement; TIA $=$ transient ischemic attack; other abbreviations as in Tables 1 and 2.

VARC-2 DEVICE SUCCESS. A high rate of VARC-2 device success $(91.7 \%)$ was obtained in our realworld TAVR population treated with the latest generation NEO and PRO THVs, with a similar rate between both treatment groups (NEO 92.0\%, PRO 90.7\%). This finding was confirmed also after adjustment for PS quintiles and in the PS-matched groups (251 pairs). Furthermore, the rates of moderate-tosevere PAR and elevated gradients (mean AV gradient $\geq 20 \mathrm{~mm} \mathrm{Hg}$ ) were comparable between the NEO and PRO groups.

Recently, the prospective Evolut PRO US Clinical Study reported a high rate of device success with the PRO device (84.0\%) (6). Regarding the NEO valve, a very high device success rate $(98.7 \%)$ was reported in the largest available prospective registry (5), whereas 2 recent studies reported similar rates $(89.0 \%$ and $89.6 \%)$ compared with our NEOPRO registry $(14,15)$. Pending the results of the SCOPE II trial, there is a lack of randomized data comparing the safety and performance of self-expanding THVs. In this context, our study reports a similar rate of VARC-2 device success between the next-generation NEO and PRO valves, also after adjustment for a range of baseline clinical and anatomic variables that may affect procedural outcome.

PARAVALVULAR LEAK. In our study, the incidence of moderate-to-severe PAR prior to discharge was $5.3 \%$, with a similar rate after NEO and PRO implantation (5.2\% vs. 5.7\%); this finding was confirmed also after adjustment for PS quintiles and in the PS-matched cohort. The PRO device was specifically designed to enhance annular sealing compared with the earlier generation Evolut $\mathrm{R}$ (by means of an external pericardial wrap), thus aiming to reduce PAR. As a result of progressive device evolution, the rate of moderate-to-severe PAR after TAVR has been progressively reduced with iterations of CoreValve THVs: $8 \%$ to $10 \%$ with the first-generation CoreValve $(10.5 \%$ in the CoreValve US Pivotal Extreme Risk Trial [16], 7.8\% in the CoreValve US 
Pivotal High Risk Trial [17], and 8.6\% in the CHOICE [Comparison of Transcatheter Heart Valves in High Risk Patients With Severe Aortic Stenosis] trial [18]), $2 \%$ to $3 \%$ with the second-generation Evolut R $(3.1 \%$ in the CoreValve Evolut R US Study [19], 2.0\% in the CoreValve Evolut R FORWARD Study [20]), and 0\% with the latest generation $\mathrm{PRO}$ in the recent Evolut PRO US Clinical Study (6). In our registry, we observed a higher rate of moderate-to-severe PAR after PRO implantation (5.7\%) compared with the Evolut PRO US Clinical Study (0\%) (6). This finding may be partially explained by the high percentage of patients with moderate to heavy AV calcification (84.2\%) and any LVOT calcification (48.0\%) treated with PRO THV in our registry. This may reflect a selection bias on the part of the operators who choose the PRO in more challenging anatomies. The degrees of AV and LVOT calcification were not reported in the Evolut PRO US Clinical Study, thus preventing a comparison of anatomic characteristics between the 2 patient populations. The NEO device features a pericardial sealing skirt to minimize PAR and was associated with a moderate-to-severe PAR rate of $4 \%$ to $5 \%$ in previous studies $(4,5,14)$. In our study, the incidence of significant PAR after NEO implantation was similar to that in previous NEO studies (5.2\%), with no differences compared with the latest generation PRO valve. Not surprisingly, we observed a higher rate of both pre-dilatation and post-dilatation in the NEO group, which may be related to the lower radial force of this prosthesis and could have had an impact on mitigating pre-discharge PAR rate. Although there was no difference in significant PAR at discharge, the lower rates of PAR may have been obtained at the price of a higher need for predilatation and post-dilatation with NEO implantation, procedural steps that could potentially be linked to a higher risk for adverse events such as annular rupture, conduction disturbances requiring PPI (15), or cerebrovascular events $(21,22)$.

Despite a similar rate of moderate-to-severe PAR between the NEO and PRO groups, the overall amount of PAR was higher after NEO implantation in the entire population, driven by a higher rate of mild PAR in this group (56.9\% vs. $42.1 \%$ ). Because residual mild PAR has been associated with worse prognosis $(23,24)$ and TAVR is expanding toward lower risk, younger, and asymptomatic patients with expected longer survival (3), we hope that future studies will further evaluate the impact of mild PAR after TAVR.

New PERmanent pacemaker. New conduction disturbances requiring PPI still represent a major concern of TAVR procedures, with highly variable rates reported for both early- and next-generation devices (25). In our registry, the incidence of new PPI at 30 days was significantly higher after PRO implantation in the entire population $(13.2 \%$ vs. $8.8 \%)$, but this difference was not maintained after adjustment for PS quintiles (OR $\mathrm{OR}_{\mathrm{aj}}: 1.49 ; 95 \% \mathrm{CI}: 0.93$ to $2.39 ; \mathrm{p}=0.100$ ) and in the PS-matched cohort (12.8\% vs. $11.0 \%)$. The rate of new PPI after NEO implantation observed in our study $(8.8 \%$ in the overall cohort, $\mathbf{1 1 . 0 \%}$ in the PS-matched cohort) is consistent with rates reported in previous studies evaluating this device (8\% to $12 \%)(4,5,14,15,26)$. Regarding CoreValve THVs, a progressive reduction in the incidence of 30-day new PPI has been observed with device iterations: $20 \%$ to $38 \%$ with the firstgeneration CoreValve $\mathbf{2 1 . 6 \%}$ in the CoreValve US Pivotal Extreme Risk Trial [16], 19.8\% in the CoreValve US Pivotal High Risk Trial [17], 37.6\% in the CHOICE Trial [18]), $16 \%$ to $20 \%$ with the secondgeneration Evolut R (16.4\% in the CoreValve Evolut R US Study [19], $19.7 \%$ in the CoreValve Evolut R FORWARD Study [20]), and $11.8 \%$ with the latest generation PRO in the Evolut PRO US Clinical Study (6). This improvement may be determined by several reasons, including device evolution, technical refinement, careful patient selection, and increased operator experience with new Evolut THV delivery features (such as resheathing and recapturing). The rate of new PPI after PRO observed in our registry (13.2\% in the overall cohort, $12.8 \%$ in the PS-matched cohort) is consistent with that reported in the Evolut PRO US Clinical Study (11.8\%) (6). Our findings confirm an acceptable incidence of new PPI with both next-generation self-expanding devices, with no significant differences between the NEO and PRO THVs after adjustment for potential clinical and anatomic confounders.

VARC-2 EARLY SAFETY COMPOSITE ENDPOINT AND CLINICAL OUTCOMES AT 30 DAYS. The patient population of the NEOPRO registry represents a realworld TAVR population with mean age of 82 years and increased surgical risk, thus reflecting current clinical practice. The VARC-2 early safety composite endpoint occurred in $\mathbf{1 5 . 2 \%}$ of patients in the entire population, significantly more common after NEO implantation (16.4\% vs. $10.9 \%)$, but this difference was not maintained after adjustment for PS quintiles $\left(\mathrm{OR}_{\mathrm{adj}}\right.$ : 0.76; 95\% CI: 0.48 to $\left.1.20 ; \mathrm{p}=0.234\right)$ and in the PS-matched cohort (10.6\% vs. $10.4 \%)$. Overall rates of all-cause mortality (2.8\%), cardiovascular mortality $(2.1 \%)$, any stroke $(2.1 \%)$, and disabling 
stroke (1.6\%) at 30 days were very low in our study, consistent with previous studies evaluating NEO and PRO devices $(4-6,14)$. Importantly, there were no significant differences in these major clinical outcomes between the 2 treatment groups. Four cases of coronary obstruction were observed in our registry, which seemed to be related to periprocedural complications (annular rupture, valve embolization, and emergent valve-in-valve implantation) or unexplained coronary thrombosis and not to specific device-related features. In the entire population, rates of any vascular complication and any bleeding were significantly higher after NEO implantation, with no significant difference in major vascular complications, life-threatening bleeding, and major bleeding between the groups. Although these differences may be related to the use of different vascular closure techniques between groups or to the lower profile of the transfemoral delivery system of the PRO THV (16-F sheath) compared with the NEO device (20-F sheath), it is worth mentioning that such differences were not maintained after adjustment for PS quintiles and in the PS-matched cohort. Overall, good clinical outcomes at 30 days were observed with both devices in our registry, reflecting current TAVR standards with next-generation THVs $(3,27,28)$.

STUDY LIMITATIONS. Our study had a retrospective observational design, with no core laboratory analysis of procedural results and independent adjudication of clinical events. We performed PS adjustment and PS-matched comparison to overcome differences in baseline characteristics and potential confounders; however, a potential impact of unknown or unmeasured confounding factors on study outcomes cannot be excluded. Furthermore, the different sample sizes between the NEO and PRO groups in the overall cohort and the relatively small numbers of patients and events in the PS-matched groups may have influenced study results.

\section{CONCLUSIONS}

In this multicenter registry, transfemoral TAVR with the NEO and PRO bioprostheses was associated with high device success, acceptable rates of moderate-tosevere PAR, and good 30-day clinical outcomes. After adjustment for potential confounders by means of PSmatched analysis, short-term outcomes were similar between the 2 next-generation self-expanding devices.

ADDRESS FOR CORRESPONDENCE: Dr. Azeem Latib, Department of Cardiology, Montefiore Medical Center, 111 East 210th Street, Bronx, New York 10467. E-mail: alatib@gmail.com.

\section{PERSPECTIVES}

WHAT IS KNOWN? To date, no study exists comparing TAVR with the next-generation selfexpanding NEO and PRO THVs.

WHAT IS NEW? In the multicenter NEOPRO registry, transfemoral TAVR with the NEO and PRO was associated with high device success, acceptable rates of moderate-to-severe PAR, and good 30-day clinical outcomes. After adjustment for potential confounders, short-term outcomes were similar between the 2 next-generation self-expanding devices.

WHAT IS NEXT? Future randomized trials and observational studies are needed to further explore procedural success and short-term outcomes after TAVR with self-expanding devices, provide insight into long-term outcomes and device durability, and identify the subsets of patients gaining the most benefit from implantation of a specific self-expanding THV.

\section{REFEREN CES}

1. Baumgartner H, Falk V, Bax JJ, et al. 2017 ESC/ EACTS guidelines for the management of valvula heart disease. Eur Heart J 2017;38:2739-91.

2. Nishimura RA, Otto CM, Bonow RO, et al. 2017 AHA/ACC focused update of the 2014 AHA/ACC guideline for the management of patients with valvular heart disease: a report of the American College of Cardiology/American Heart Association Task Force on Clinical Practice Guidelines. J Am Coll Cardiol 2017;70:252-89.

3. CahillTJ, Chen M, Hayashida K, et al. Transcatheter aortic valve implantation: current status and future perspectives. Eur Heart J 2018:39:2625-34.
4. Möllmann $H$, Walther $T$, Siqueira $D$, et al. Transfemoral TAVI using the self-expanding ACURATE neo prosthesis: one-year outcomes of the multicentre "CE-approval cohort." EuroIntervention 2017;13:e1040-6.

5. Möllmann $\mathrm{H}$, Hengstenberg $\mathrm{C}$, Hilker $\mathrm{M}$, et al. Real-world experience using the ACURATE neo prosthesis: 30 -day outcomes of 1,000 patients enrolled in the SAVI TF registry. Eurolntervention 2018;13:e1764-70.

6. Forrest JK, Mangi AA, Popma JJ, et al. Early outcomes with the Evolut PRO repositionable self-expanding transcatheter aortic valve with pericardial wrap. J Am Coll Cardiol Intv 2018;11: $160-8$

7. Barbanti $M$, Yang $T-H$, Rodès Cabau J, et al Anatomical and procedural features associated with aortic root rupture during balloonexpandable transcatheter aortic valve replacement. Circulation 2013;128:244-53.

8. Möllmann $H$, Diemert $P$, Grube $E$, Baldus $S$, Kempfert J, Abizaid A. Symetis ACURATE TFTM aortic bioprosthesis. Eurolntervention 2013;9 Suppl:S107-10.

9. Manoharan G, Walton AS, Brecker SJ, et al, Treatment of symptomatic severe aortic stenosis 
with a novel resheathable supra-annular selfexpanding transcatheter aortic valve system. J Am Coll Cardiol Intv 2015;8:1359-67.

10. Kappetein AP, Head SJ, Généreux P, et al. Updated standardized endpoint definitions for transcatheter aortic valve implantation: the Valve Academic Research Consortium-2 consensus document. J Am Coll Cardiol 2012; 60:1438-54.

11. D'Agostino RB. Propensity score methods for bias reduction in the comparison of a treatment to a non-randomized control group. Stat Med 1998; 17:2265-81.

12. Rubin DB. Estimating causal effects from large data sets using propensity scores. Ann Intern Med 1997;127:757-63.

13. Caliendo M, Kopeinig S. Some practical guidance for the implementation of propensity score matching. J Econ Surv 2008;22:31-72.

14. Husser $O$, Kim W-K, Pellegrini $C$, et al. Multicenter comparison of novel self-expanding versus balloon-expandable transcatheter heart valves. J Am Coll Cardiol Intv 2017;10:2078-87.

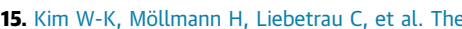
ACURATE neo transcatheter heart valve: a comprehensive analysis of predictors of procedural outcome. J Am Coll Cardiol Intv 2018;11: $1721-9$.

16. Popma JJ, Adams DH, Reardon MJ, et al. Transcatheter aortic valve replacement using a self-expanding bioprosthesis in patients with severe aortic stenosis at extreme risk for surgery. J Am Coll Cardiol 2014;63:1972-81.

17. Adams DH, Popma JJ, Reardon MJ, et al. Transcatheter aortic-valve replacement with a self-expanding prosthesis. N Engl J Med 2014; 370:1790-8.

18. Abdel-Wahab M, Mehilli J, Frerker C, et al. Comparison of balloon-expandable vs selfexpandable valves in patients undergoing transcatheter aortic valve replacement: the CHOICE randomized clinical trial. JAMA 2014; 311:1503-14.

19. Popma JJ, Reardon MJ, Khabbaz K, et al. Early clinical outcomes after transcatheter aortic valve replacement using a novel self-expanding bioprosthesis in patients with severe aortic stenosis who are suboptimal for surgery: results of the Evolut R U.S. Study. J Am Coll Cardiol Intv 2017; 10:268-75.

20. Grube $E$, Van Mieghem NM, Bleiziffer $S$, et al. Clinical outcomes with a repositionable selfexpanding transcatheter aortic valve prosthesis: the international FORWARD study. J Am Coll Cardiol 2017;70:845-53.

21. Nombela-Franco L, Rodés-Cabau J, DeLarochellière $R$, et al. Predictive factors, efficacy, and safety of balloon post-dilation after transcatheter aortic valve implantation with a balloon-expandable valve. J Am Coll Cardiol Intv 2012;5:499-512.

22. Nombela-Franco L, Webb JG, de Jaegere PP, et al. Timing, predictive factors, and prognostic value of cerebrovascular events in a large cohort of patients undergoing transcatheter aortic valve implantation. Circulation 2012;126:3041-53.

23. Kodali $S$, Pibarot $P$, Douglas PS, et al. Paravalvular regurgitation after transcatheter aortic valve replacement with the Edwards SAPIEN valve in the PARTNER trial: characterizing patients and impact on outcomes. Eur Heart J 2015;36:449-56.

24. Gerckens $U$, Tamburino $C$, Bleiziffer $S$, et al. Final 5-year clinical and echocardiographic results for treatment of severe aortic stenosis with a selfexpanding bioprosthesis from the ADVANCE study. Eur Heart J 2017;38:2729-38.

25. van Rosendael PJ, Delgado V, Bax JJ. Pacemaker implantation rate after transcatheter aortic valve implantation with early and new-generation devices: a systematic review. Eur Heart J 2018;39: 2003-13.

26. Mauri $V$, Kim WK, Abumayyaleh $M$, et al. Short-term outcome and hemodynamic performance of next-generation self-expanding versus balloon-expandable transcatheter aortic valves in patients with small aortic annulus: a multicenter propensity-matched comparison. Circ Cardiovasc Interv 2017;10:e005013.

27. Jones BM, Krishnaswamy A, Tuzcu EM, et al. Matching patients with the ever-expanding range of TAVI devices. Nat Rev Cardiol 2017;14:615-26.

28. Puri R, Chamandi C, Rodriguez-Gabella $T$, Rodés-Cabau J. Future of transcatheter aortic valve implantation - evolving clinical indications. Nat Rev Cardiol 2018;15:57-65.

KEY WORDS Acurate neo, Evolut PRO, self-expanding, TAVR, VARC-2

APPENDIX For a supplemental table and figure, please see the online version of this paper. 